\title{
Design and Implementation of Webpage Addition Technology in Aerobics Courses
}

\author{
http://dx.doi.org/10.3991/ijet.v11i09.6118 \\ Yingying Zheng \\ Wenzhou University, Wenzhou, China
}

\begin{abstract}
The rapid development of modern information technology facilitates the reform and innovation of college teaching. A series of technologies, including webpage addition technology, can meet the requirement of aerobics and other shape-related teaching for animation display. Thus, webpage addition technology is a new viewpoint in the education modernization process. The combination of webpage addition technology and Aerobics courses will provide help for Aerobics teaching. Starting from teaching features and the website learning status of Aerobics courses, this paper carried out an application design for webpage addition design. Then, an Aerobics course served as an experimental course. The control experiment method was applied to explore the application practice of webpage addition technology in the control experiment. Furthermore, this paper conducted contrastive analysis on the teaching effect difference with and without webpage addition technology, and drew some conclusions, in the hope of offering reference for combining webpage addition technology with Aerobics courses.
\end{abstract}

Index Terms-modern information technology, webpage addition technology, aerobics course, animation

\section{INTRODUCTION}

As computer technology and internet technology continuously develops, more and more teaching systems based on learning website have started to appear. These teaching systems present a significant application value in college teaching. Teachers are gradually gaining access to learning websites in classroom teaching, and students also increasingly approve of such new teaching mode [1]. Website learning, as an assisted teaching means, plays a significant role in deepening classroom teaching effect, and expanding and supplementing teaching resources. Meanwhile, high-quality multimedia courseware and superior database resources enhance the students' learning interest and improve their independent learning effect and ability [2].

Černá et al. [3] conducted a study on the development of language and digital competences among college students through usability testing of English websites by students themselves. Results show that the college students affirm that the new method knows the chosen websites and that the college students are ready to participate in the education process. Students are taught to master the methods of exploring language websites, learning how to move ahead in them, applying functionalities, such as connection to social applications, practice tests, or self-diagnosis of language competence. Some researchers [4] proposed a mobile learning support system (MLSS) by which students obtained learning materials and utilized two-dimensional barcode technology and GPS technology. Learning information was obtained from online websites by camera-equipped mobile phones and 2D barcode tags. Experimental results indicate that MLSS can improve the students' learning effect. Wang and Vásquez [5] summarized the researches on the application of Web 2.0 technologies in second language study. Results show that blogs and wikis are the most commonlyused Web 2.0 tools, and the largest benefit brought by Web 2.0 technologies is the good language learning environment that the technologies help to create.

As a typical example of shape-related teaching, Aerobics combines gymnastics, music, and dance. Aerobics not only contributes to the participants' physical and psychological health, but can also shape the body and cultivate the students' taste [6]. The Aerobics course is among the college PE courses. In this course, students can increase their knowledge and skills, while building the body. Aerobics learning has high requirements for movement standard and arrangement ability. Thus, the application of modern teaching technology is necessary [7]. With the help of website learning and animation appreciation, students can experience a visual feeling of specific movements in a more realistic, accurate, and standard manner. However, existing Aerobics course learning websites are still limited to theoretical knowledge and fail to give full play to the characteristics of modern network technology. Webpage addition technology will highlight the decomposition of detailed movements and present the key points of course learning. Xiang et al. explored the application of multimedia technology in Aerobics teaching, thoroughly analyzed the advantages and disadvantages of multimedia teaching, discussed the potential problems in daily teaching, and proposed corresponding suggestions [8]. Other researchers applied online learning websites in Aerobics teaching, and adopted a contrasting experiment to test and evaluate 57 female college students. Results indicate that online learning websites can significantly boost skilled bodily movements and improve exercise quality and psychological quality [9].

Based on the aforementioned researches, there have been no researches on Cascading Style Sheet (CSS) animation addition in Aerobics learning websites. In previous technologies, CSS files of HTML documents must be edited in the editor to add animations in the webpage. To know the CSS animation effect, there is a need to switch to a browser and obtain edited HTML documents through the browser, and then to refresh to preview the CSS animation effect. This process is repeated over and over again, which results in a low editing efficiency of CSS animation [10]. The present paper aims to study the application of webpage addition technology in Aerobics courses. The present paper 
introduced a new webpage addition technology by which animation can be added in learning websites to design the webpage that can better comply with teaching requirements. In the current experiment, the application effect of new webpage addition technology will be explored through result contrast. The experimental results will be discussed and analyzed to offer guidance for the application of webpage addition technology and teaching practice of Aerobics courses.

\section{Design Of WebPage AdDition Technology APPLICATION}

CSS is a kind of computer language used to express file style, such as HTML (an application of Standard Generalized Markup Language) or XML (a subset of Standard Generalized Markup Language) [11]. The present paper adopted the Standard Generalized Markup Language version of CSS - CSS3 [12].

The method of adding animations to a webpage is as follows: first, load the webpage document that contains animation addition identification - HTML page element and acquire the HTML page; second, add CSS3 animation in the corresponding page element of the HTML page through the animation selection window, and carry out rendering exhibition; finally, add the CSS3 code corresponding to the CSS3 animation, and add the CSS3 code to the corresponding positions of the webpage document editor and page element. Before the animation selection window starts, there is a need to monitor the triggering operation on the page element of the corresponding animation addition identification. During the addition of the CSS3 animation, attributes, such as animation duration, animation delay, and the animation cycle index of CSS3 animation, should be chosen in the animation selection window. Before the CSS3 code is added, the prompt content at the animation addition position in the HTML page element should be deleted from the webpage document editor. The application steps of webpage addition technology are shown in Figure 1.

The application device of webpage addition technology includes three modules: HTML page loading module, real-time animation display module, and code editing and modification module. The HTML page loading module is used to load the webpage document in which CSS3 animation is to be added and to obtain the HTML page to be processed. The real-time animation display module is used to choose animations, add CSS3 animation in the HTML page, and render exhibition. The code editing and modification module is used to complete code addition, and add CSS3 code in the specified position. The realtime animation display module involves selective monitoring, interface starting, and real-time display modules, which can achieve the functions of monitoring the HTML page element triggering operation, starting the animation selection window, and displaying CSS3 animations in real time. The real-time display module further contains two modules: attribute information confirmation and prompt content deletion. The duration, delay, and cycle index of CSS3 animation can be chosen in attribute information confirmation module.

A schematic diagram of the application device module of webpage addition technology is shown in Figure 2. The application effect of webpage addition technology is shown in figure 3 and figure 4.

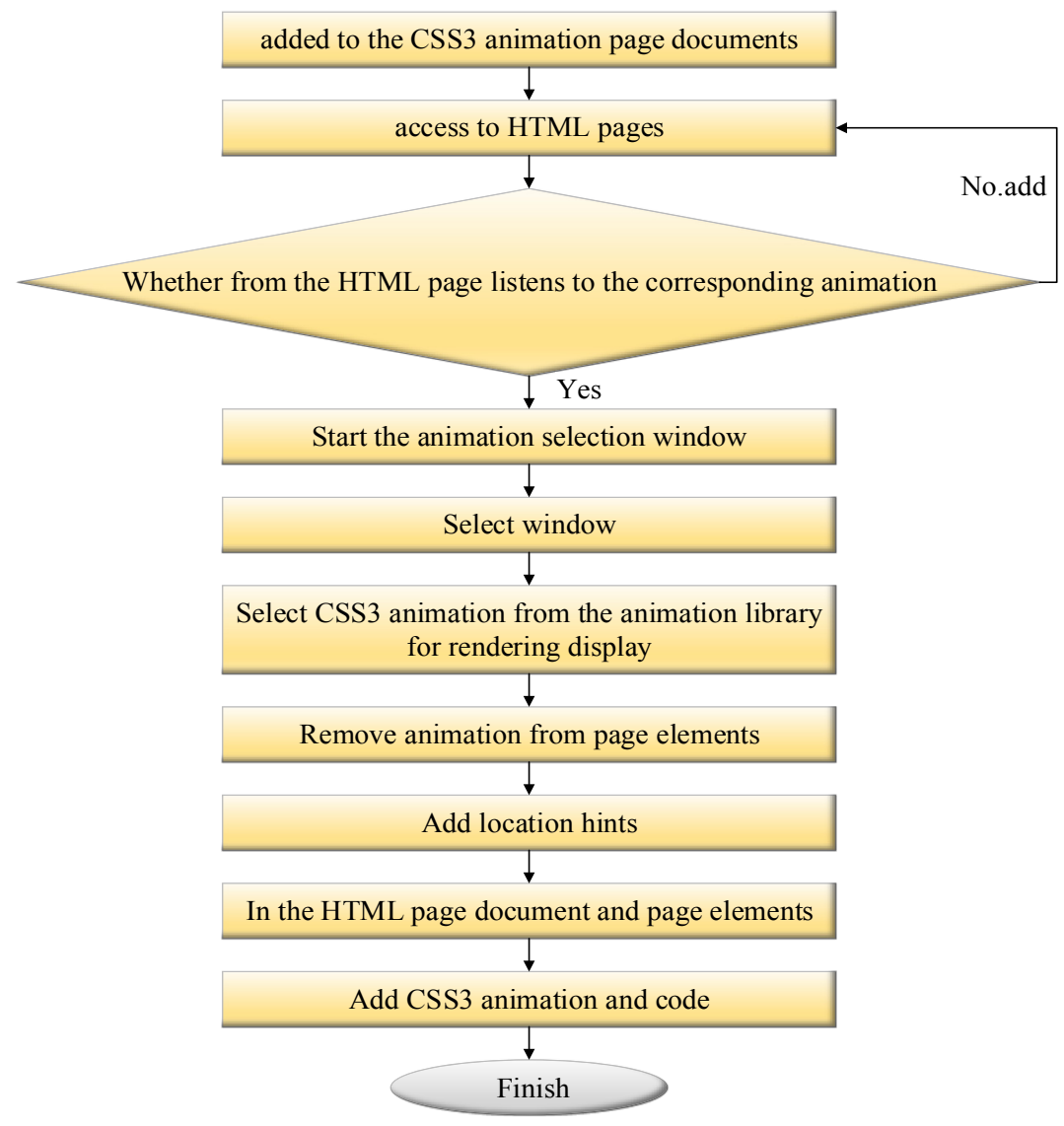

Figure 1. Application steps of webpage addition technology 


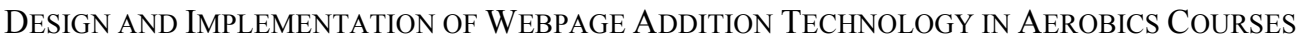

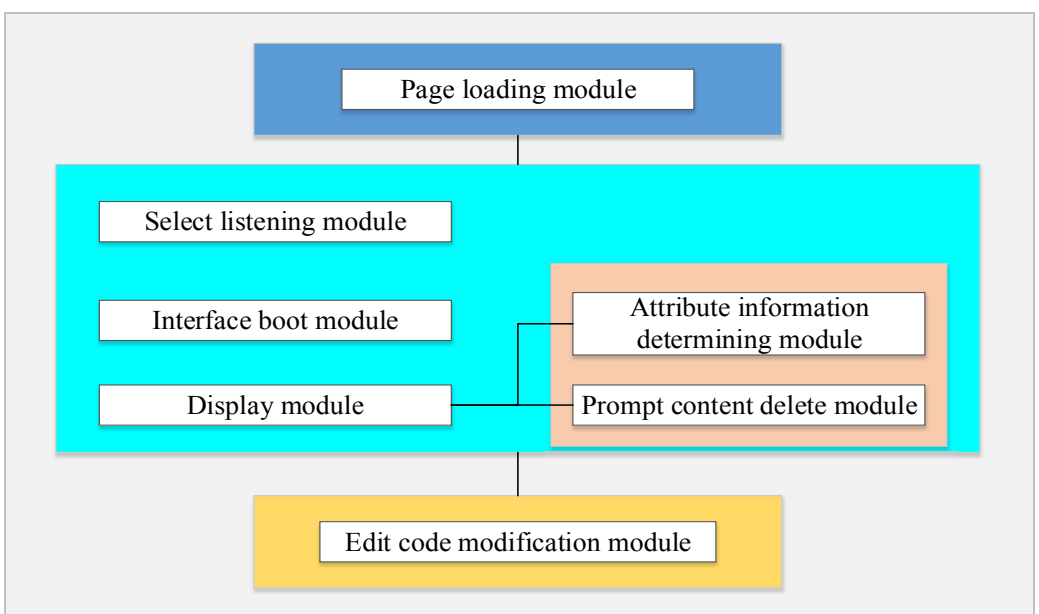

Figure 2. Schematic diagram of application device module of webpage addition technology

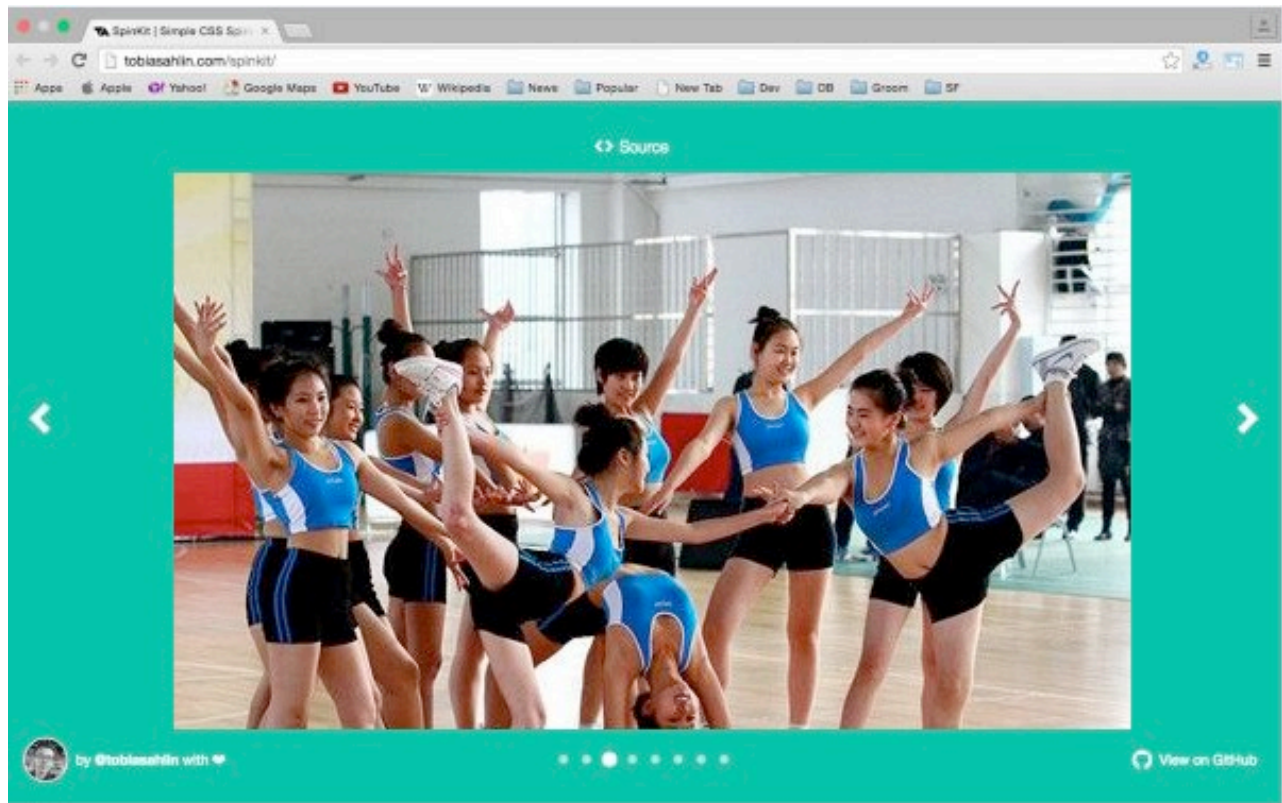

Figure 3. Interface diagram of aerobics learning website

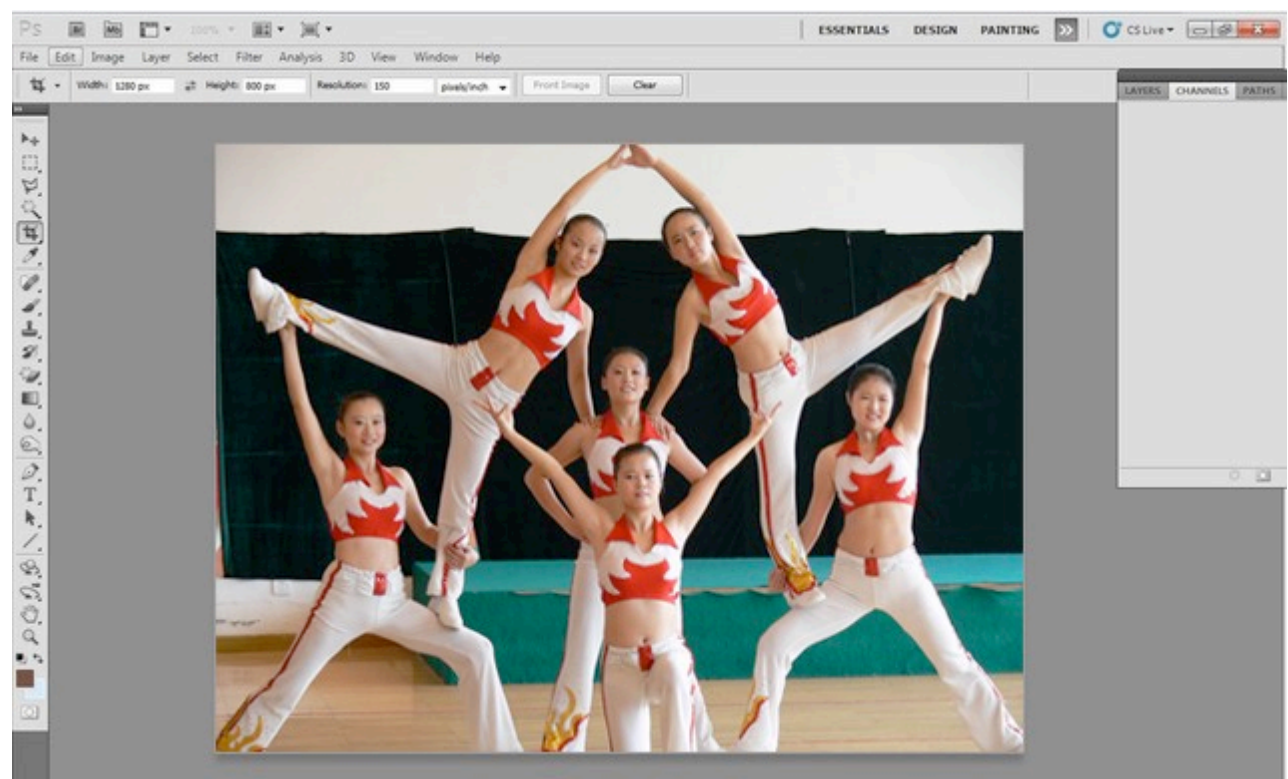

Figure 4. Display diagram of aerobics animation 


\section{APPLICATION EXPERIMENT OF WEBPAGE Addition TeCHNOLOGy In AEROBICS COURSE}

\section{A. Objects of study}

In the current experiment, sophomores from a physical education school in a university were chosen as the objects of study. Among the five classes, one class (composed of 50 students) was drawn at random as the experimental class for which webpage addition technology was applied to assist teaching. Another class (composed of 50 students) was drawn at random as the control class for which traditional teaching mode was applied. There were no significant differences between the experimental class and the control class in teaching teachers and teaching conditions. The age, gender, physical quality, and comprehensive ability of students in both classes had no significant differences. The learning content consisted of three parts: theory, practice, and special training. After the course, comparative analysis was made for the experimental class and control class.

\section{B. Research method}

Control group: The experimental group was not processed by webpage addition technology. Experimental group: The learning website was processed by webpage addition technology.

\section{Design and implementation of teaching experiment}

There were 36 class hours for the Aerobics course. First, the teaching objective was to make students master the basic knowledge and basic movements of aerobics exercise and train their rhythm sense and rhythm sensation. Second, the teaching objective was for students to learn arrangement mode and aerobics exercise methods and to improve the students' arrangement ability and creativity. Finally, the teaching objective was to form the students' physical exercise habit and the awareness of lifelong sports. For these objectives, the teaching contents of the Aerobics course comprised three parts: theory, practice, and special training. The theory covered basic terms, competition rules, music, and arrangement of aerobics, for 15 class hours in total. The practice was divided into four levels according to the standards of mass aerobics exercise, for a total of 12 class hours. The special training focused on basic movement combinations of aerobics, strength, and flexibility practice, for a total of 9 class hours.

The teaching progress was matched with class hour arrangement. The teaching was implemented by the same teacher, and the same teaching mode was applied. The theory course and practice course were synchronously conducted. After the practice course, the special training course started. In theory course teaching, the experimental class was taught with the learning website processed by webpage addition technology to enhance the display of detailed aerobics movements. The control class adopted the previous learning website. Both classes reviewed through the corresponding learning website provided by the teacher after class, remembered and combined basic movements learned in class, and previewed the content of the next class hour. Movement display and requirements were published by the learning website in practice course and special training course to emphasize the students' independent study and clearly know the essentials of movements and examination requirements.

The students' learning effect was mainly obtained through the examination at the end of the semester. The examination was divided into three parts: basic theory examination, grade routine, and innovative arrangement. Each part was examined separately. The full score was 100. The separation of teaching and examination was adopted for examination and evaluation. The examination teacher was a different teacher from the course teacher. The examination score was independent of classroom performance. Thus, such examination mode was more objective and fair. Basic theory examination put particular emphasis on basic terms and competition rules. Grade routine examination scored the students' aerobics display from the perspective of movement standard, proficiency, and richness. Students were required to freely form groups (composed of 3-5 students per group) in innovative arrangement examination. Each group needed to arrange ten 8-beat aerobics movements, and each 8-beat movement was repeated at different directions. At least six 8-beat movements should be different. The examination teacher gave scores on various aspects, such as the matching degree of movements and music, overall display effect, knowledge connotation reflected in the movements arranged, and group characteristics.

\section{TEAChing Influence OF Webpage AdDition TEChNOLOGY ON AEROBICS COURSE TEACHING}

The present paper explored the influence of webpage addition technology on Aerobics course teaching from three aspects: basic knowledge and content contrast, statistical analysis of examination scores, and innovative arrangement ability.

\section{A. Contrast of learning website contents}

Based on Table 1, compared with the control group, the animation display link is added for the experimental group in the theory course, practice course, and special training course, and the application of webpage addition technology is apparent. In learning theoretical knowledge, the control group's course content arrangement is dull and lays particular stress on the introduction to the text and static pictures. The experimental group can acquire aerobics movement details in a three-dimensional manner through animation display of competition rules and arrangement effect to deepen the understanding of terms. In the practice course, the animation display of movement details and paces is added in the learning website adopted by the experimental class. Furthermore, all kinds of music can be chosen for formation arrangement. Thus, the practicability and matching degree are higher. In the special training course, the experimental group can know the effect of the movement combination in time through animation display of aerobics movement combination and apply the effect to create an innovative arrangement.

\section{B. Statistical analysis of scores}

The comparison of scores of both classes is as figure 5 .

Table 1 also shows that among the three modules contained in the final examination, the experimental class' average score is higher than that of control class. In the examination of basic theory knowledge, the experimental group's score is slightly higher than that of control group. 


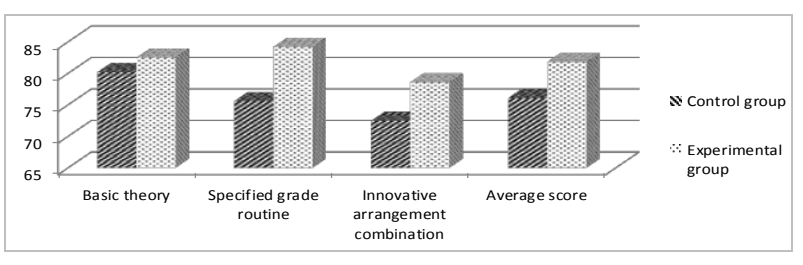

Figure 5. Comparison of scores of both classes

The experimental group's examination score is significantly higher than that of control group. The experiment proves that the application of webpage addition technology in Aerobics course teaching shows significant improvement effects, and the students' average sore increases by a large margin.

Table 1 further shows that the final examination score distribution of both classes differs. The excellent rate and good rate of the experimental class significantly improved, whereas the pass rate and failure rate further decreased. The control class' total score is mostly concentrated between good and pass, and the pass rate cannot be ignored. The total score of most students in the experimental class is in the excellent and good groups, and the improvement effect is significant.

\section{Comparison of students' innovative arrangement ability}

Based on Table II, the innovative arrangement ability of students in the experimental class significantly improved compared with the students in the control class. In addition, the students in the experimental class presented more standard movements (including self-arranged movements), more formation change times, and more fluent overall arrangement effect. The students in the control group mostly recombined the contents learned, and the innovation is not evident. Furthermore, the students failed to understand aerobics well.

The current experiment indicates that the application of webpage addition technology in the Aerobics course has significant effects. Webpage addition technology can achieve animation addition in the webpage, assist aerobics teaching, and improve teaching efficiency. Most students approve of the animation display of the animation form.
Animation display, which is achieved with the help of webpage addition technology, can effectively stimulate the students' learning interest and reduce learning difficulties. Animation display is characterized by combined picture and texts, color change, and strong rhythm sense. Thus, animation display can significantly make up for the defects of previous teaching movement demonstrations, and get rid of the series of restrictions of the traditional teaching mode. Meanwhile, animation richness conforms to the students' psychological situation and emotional experience, and students can establish clear movement representation for aerobics movements. Through animation freeze-frame, low speed, and repetition, each detail of skilled movement can be displayed for students, and the essentials of movements are prominent.

Information technology based on webpage addition technology as a teaching tool has a rich functional value in aerobics teaching. First, the teaching content assisted by information technology becomes richer and more flexible. Teachers have more teaching materials and means, and the teaching forms are more flexible. Teachers may adopt different teaching modes according to diverse teaching contents. Second, the key and difficult points further stand out in the teaching process, and the details are more accurate. In aerobics and other shape teaching, teachers no longer need to repeat movement demonstration. The teachers can continuously amplify and play back skilled movements with the help of animation display. Moreover, students are in the imitative status in the learning process and no longer excessively depend on teachers. The students can improve their knowledge level through website learning.

\section{CONCLUSION}

Webpage addition technology complies with the teaching requirements of the Aerobics course and has good teaching effects. Webpage addition technology plays a significant role in achieving teaching reform objectives and improving teaching quality. Thus, the application prospect of webpage addition technology and other modern information technology in aerobics and shape-related teaching is very broad. Therefore, webpage addition technology deserves promotion.

TABLE I.

LEARNING CONTENT CONTRAST OF EXPERIMENTAL CLASS AND CONTROL CLASS

\begin{tabular}{|l|l|l|l|}
\hline \multicolumn{1}{|c|}{ Learning content } & \multicolumn{1}{|c|}{ Theory course } & \multicolumn{1}{|c|}{ Practice course } & \multicolumn{1}{c|}{ Special training course } \\
\hline Control class & $\begin{array}{l}\text { A Basic terms, competition } \\
\text { rules, music and arrangement }\end{array}$ & $\begin{array}{l}\text { A Basic movement demonstration; basic pace demon- } \\
\text { stration } \\
\text { B Innovation arrangement according to the routine } \\
\text { learned }\end{array}$ & $\begin{array}{l}\text { A Strength and flexibility } \\
\text { training } \\
\text { B Aerobics movement combi- } \\
\text { nation }\end{array}$ \\
\hline Experimental class & $\begin{array}{l}\text { A Same with the above } \\
\text { B Animation display of compe- } \\
\text { tition rules, animation display } \\
\text { of arrangement effect }\end{array}$ & $\begin{array}{l}\text { A Same with the above } \\
\text { B Same with the above } \\
\text { C Animation display of detailed movements; animation } \\
\text { display of paces } \\
\text { D Choose all kinds of music for arrangement }\end{array}$ & $\begin{array}{l}\text { A Same with the above } \\
\text { B Same with the above } \\
\text { Cics movement combination }\end{array}$ \\
\hline
\end{tabular}

TABLE II.

COMPARISON OF STUDENTS' INNOVATIVE ARRANGEMENT ABILITY

\begin{tabular}{|c|c|c|c|c|}
\hline Class & Movement standard & Movement section & $\begin{array}{c}\text { Formation change (average } \\
\text { times) }\end{array}$ & $\begin{array}{c}\text { Overall arrangement } \\
\text { effect }\end{array}$ \\
\hline Control class & Low & Choose from grade routine & 4-6 times & Common \\
\hline Experimental class & High & Self-arranged movement & 6-8 times & Fluent \\
\hline
\end{tabular}




\section{REFERENCES}

[1] Smith D., Mclaughlin T., Brown I., "3-D Computer Animation vs. Live-Action Video: Differences in Viewers' Response to Instructional Vignettes," Contemporary Issues in Technology \& Teacher Education, vol. 12, no. 1, pp. 41-54, March 2012.

[2] Aksoy G., "Effect of Computer Animation Technique on Students' Comprehension of the," Mevlana International Journal of Education, vol. 3 no. 1, pp. 40-46, April 2013. http://dx.doi.org/10.13054/mije.13.02.3.1

[3] Roth W.J., Shvets O.V., Shamzhy M., et al., "Postsynthesis Transformation of Three-Dimensional Framework into a Lamellar Zeolite with Modifiable Architecture," Journal of the American Chemical Society, vol. 133, no. 16, pp. 6130-6133, April 2011. http://dx.doi.org/10.1021/ja200741r

[4] Wang S., "Motions Blur Effects in the Process of ThreeDimensional Animation Technology Research," Applied Mechanics \& Materials, vol. 687-691, pp. 1170-1173, November 2014. http://dx.doi.org/10.4028/www.scientific.net/AMM.687-691.1170

[5] Yan B., "Physical Education Based on PE Physical Education Technology," Sports World (Scholarly), no. 9, pp. 74-75, September 2010 .
[6] Cui J.G., Wang Z.S., "Enlightenment of Multimedia Network Platform on College PE," News Front, no. 12, pp. 50-51, June 2015.

[7] Musa S., Ziatdinov R., Sozcu O.F., et al., "Developing Educational Computer Animation Based on Human Personality Types," Social Science Electronic Publishing, vol. 11, no. 1, pp. 52-71, March 2015. http://dx.doi.org/10.13187/ejced.2015.11.52

[8] Liu Y., Zhong P., Liu W., "The Design of Basketball CAI Courseware Based on Internet Technology," Sichuan Sports Science, vol. 21, no. 1, pp. 63-64, March 2002.

[9] Huang R., "Digital PE Teaching Platform Based on ADDIE Model," Sports Research and Education, vol. 28, no. 5, pp. 69-72, October 2013.

\section{AUTHORS}

Yingying Zheng is a Lecturer at Wenzhou University, Institute of Physical Education, Wenzhou 325035, China. Her research interests include webpage addition technology and physical education. (zjzyy881@163.com)

Submitted 07 August 2016. Published as resubmitted by the authors 20 September 2016. 